\title{
Nonlinear Effects of Provincial Economic Growth on Environmental Pollution
}

\author{
Jian-bao CHEN \\ School of Mathematics and Computer Science \\ Fujian Normal University \\ Fuzhou, China \\ jbjy2006@126.com
}

\author{
Zi-jia WAN \\ Local Taxation Bureau of Qingying \\ Chengdu, China \\ wanzijia@foxmail.com
}

\author{
Qiong XIA* \\ School of Economics \\ Fujian Normal University \\ Fuzhou, China \\ xiaqiong816@163.com
}

\begin{abstract}
Using panel smooth transition regression (PSTR) model, we study the nonlinear effects of provincial economic growth on environmental pollution in China. The empirical research shows that the relationship between provincial economic growth and environmental pollution in China exists nonlinear smooth transition mechanism; provincial economic growth has an asymmetric effect on environmental pollution, which means that it has an negative (positive) effect when provincial GDP is less than (higher than) 2.85 trillion Yuan; the optimal provincial GDP interval is $[2.20,3.63]$ trillion Yuan, where the marginal effect is negative.
\end{abstract}

Keywords-economic growth; environmental pollution; PSTR; nonlinear influence

\section{INTRODUCTION}

China's economy has increased rapidly since the reform and opening-up policies and soon became the world second largest economy body in 2010. However, at the same time, the environment has paid a heavy price. The basic living conditions, such as soil, water and air quality, have been in downward tendency. According to the research report from World Bank, China lost 9\% of its national income each year due to the environmental deterioration, almost the same as the growth rate of annual national income. Therefore, how to control and improve the state of environmental pollution, while maintaining moderate economic growth, is a difficult task for Chinese government in the future.

The research on the relations between economic growth and environmental pollution has roughly experienced three development stages in abroad. The first stage was represented by "limits to growth" (Meadows et al., 1972). The second stage was "environmental Kuznets curve" hypothesis, Grossman and Kruger (1991) used data from 42 countries to find out "inverted U-shaped" relationship between income per capita and contaminants (sulfur dioxide and smoke-dust); Thomas et al. (1994) confirmed the "inverted U-shape" function between GDP per capita and suspended particle, sulfur dioxide, nitrogen oxides and carbon monoxide. The third stage is mainly to study the role of trade factors in the environmental Kuznets curve hypothesis. Antweiler et al. (2001) studied the influences of international trade on environmental pollution theoretically and decomposed the influences into scale, technology and compound effects, empirical results show that lower sulfur dioxide would benefit from stronger international trade.

Chinese scholars have paid much attention on the study of EKC hypothesis and turning points. $\mathrm{Lu}$ and $\mathrm{Li}$ (2009) explored the influence of social capital on environment quality under EKC framework and found out that EKC hypothesis only reflected in industrial sulfur dioxide, featuring N-shape. Su and Zhang (2011) confirmed the turning point of EKC hypothesis would right forward when income gap is overlarge by using adjusted GDP per capita through mixing urban and rural Gini coefficient. Besides to test EKC hypothesis by selecting dependent variables, Fu (2008) adopted non-parametric methods to analyze EKC curve in China. Wu et al. (2011) analyzed the spatial correlation of provincial environmental pollution by spatial econometric model.

In summary, most of the current research results were based on EKC hypothesis and less on nonlinear relation. We will testify the nonlinear relations between economic growth and environmental pollution among 30 regions (excluding Tibet) in China by PSTR model, and examines impacts of different transition variables on elasticity of economic growth with respect to environmental pollution. It dedicated to investigate the indirect influence of each region's urbanization, industrial level, FDI and liberalization on effect economic growth on environmental pollution through building up single-factor PSTR model to identify different level of impact by those four variables. It depicts the transition process of effect economic growth on environmental pollution with the changes of the four variables. It also finds out the optimal provincial GDP interval by constructing multi-factor PSTR models to analyze quantitatively the different environmental pollution impacts and marginal effect of economic scale on pollution. 
It reveals the regional heterogeneity between economic growth and environmental pollution.

\section{MethodOLOGY}

\section{A. General Panel Smooth Transition Regression Setting}

Based on panel transition regression (PTR) model (Hansen, 1999), the PSTR model was first proposed by Gonzalez et al. (2004). Its mathematical expression is as follows:

$$
y_{i t}=\mu_{i}+\beta x_{i t} I\left(q_{i t} \leq c\right)+\beta^{1} x_{i t} I\left(q_{i t}>c\right)+\varepsilon_{i t}
$$

PSTR model used a continuous transition function to replace discrete indicator function in PTR, which makes model coefficients change with transition variable continuously and smoothly. Model (1) can be expressed as follows:

$$
y_{i t}=\mu_{i}+\beta x_{i t}+\beta^{1} x_{i t} g\left(q_{i t} ; \gamma, c\right)+\varepsilon_{i t}
$$

where $q_{i t}$ is a transition variable, $\varepsilon_{i t} \square$ i.i.d. $\left(0, \sigma^{2}\right)$, transition function $g\left(q_{i t} ; \gamma, c\right)$ is a continuous and bounded function of transition variables, $i=1, \cdots, N ; t=1, \cdots, T$

The PSTR model still use the transition function from STAR model given by Granger and Teräsvirta’s (1993):

$$
g\left(q_{i t} ; \gamma, c\right)=\left[1+\exp \left(-\gamma \prod_{j=1}^{m}\left(q_{i t}-c_{j}\right)\right)\right]^{-1}, \gamma>0, c \leq \cdots \leq c_{m}
$$

where $\gamma$ is the slope parameter for transition function, which reflects transition rate or smoothness from one mechanism to the other. $c=\left(c_{1}, \cdots, c_{m}\right)^{\prime}$ is the $m$ dimensional location parametric vector and usually valued as 1 or 2 . When $m=1$, it is LSTR1 type, which is monotonically increasing of $q_{i t}$. When $q_{i t} \rightarrow-\infty$, it is showed as low mechanism in model (2). When $q_{i t} \rightarrow+\infty, g\left(q_{i t} ; \gamma, c\right) \rightarrow 1$, it is showed as high mechanism. Therefore, $g\left(q_{i t} ; \gamma, c\right)$ can be transited smoothly with $q_{i t}$ valued between $(-\infty,+\infty)$. Besides, when $\gamma \rightarrow+\infty$, transition function can only be 0 or 1 , PTSR degenerates as PTR; when $q_{i t}=c$ or $\gamma \rightarrow 0, g\left(q_{i t} ; \gamma, c\right)=0.5$, PSTR degenerates as fixed effect model. When $m=2$, it is LSTR2 type and $g\left(q_{i t} ; \gamma, c_{1}, c_{2}\right) \rightarrow 1$ only when $q_{i t} \rightarrow+\infty$.

The general PSTR setting is followed:

$$
\left\{\begin{array}{l}
y_{i t}=\mu_{i}+\beta x_{i t}+\sum_{k=1}^{l} \beta^{k} x_{i t} g_{k}\left(q_{i t}^{(k)} ; \gamma_{k}, c^{k}\right)+\varepsilon_{i t} \\
g_{k}\left(q_{i t}^{(k)} ; \gamma_{k}, c^{k}\right)=\left[1+\exp \left(-\gamma_{k} \prod_{j=1}^{m}\left(q_{i t}^{(k)}-c_{j}^{k}\right)\right)\right]^{-1}
\end{array}\right.
$$

where the relation parameter of $x_{i t}$ and $y_{i t}$ is:

$$
e_{i t}=\frac{\partial y_{i t}}{\partial x_{i t}}=\beta+\sum_{k=1}^{l} \beta^{k} g_{k}\left(q_{i t}^{(k)} ; \gamma_{k}, c^{k}\right)
$$

\section{B. Nonlinear Test}

Nonlinear test whether $\gamma=0$ or $\beta^{1}=0$ is the first step to set up PSTR model. If the nonlinearity exists, we need to estimate a PSTR model; otherwise, it is a linear fixed effect model. It is usually to take first order Taylor approximation at $\gamma=0$ for transition function $g(\cdot)$ and construct parameter linear auxiliary regression model:

$$
y_{i t}=\mu_{i}+\beta x_{i t}+\Gamma_{1}^{\prime} \sum_{k=1}^{l} \beta^{k} x_{i t} q_{i t}^{(k)}+\cdots+\Gamma_{m}^{\prime} \sum_{k=1}^{l} \beta^{k} x_{i t}\left[q_{i t}^{(k)}\right]^{m}+\varepsilon_{i t}
$$

where the null hypothesis for nonlinear test is $H_{0}: \Gamma_{1}=\cdots=\Gamma_{m}=0$ and $H_{1}: \Gamma_{1} \neq 0, \Gamma_{2}=\cdots=\Gamma_{m}=0$ for alternative hypothesis. Suppose $S S R_{0}$ and $S S R_{1}$ as panel residual sum of square under $H_{0}$ and $H_{1}$, and it may build up Wald test statistics $L M$ under $\chi^{2}$ distribution, Fisher test statistics $L M_{F}$ under $F$ distribution and LRT statistics under $\chi^{2}$ distribution (Gilbert and Hurlinz, 2006):

$$
\begin{gathered}
L M=T N\left(S S R_{0}-S S R_{1}\right) / S S R_{0} \\
L M_{F}=\left[\left(S S R_{0}-S S R_{1}\right) / K m\right] /\left[S S R_{0} /(T N-N-m K)\right] \\
L R T=-2\left[\log \left(S S R_{1}\right)-\log \left(S S R_{0}\right)\right]
\end{gathered}
$$

where $T$ is the length of time, $N$ is size of the cross section, $K$ is the number of dependent variables $x_{i t}$.

\section{Parameter Estimation}

Estimate a PSTR model when nonlinearity exists. First, determine the number of transition function $k$ through sequential test, and then determine the number of location parameter $m$ through expanding the nonlinear test above. The next stage is to estimate location parameter $c$ and slope parameter $\gamma$ by grid search or a simulated annealing algorithm iterative estimation. Finally, estimate parameters of the model through nonlinear least squares method.

\section{EMPIRICAL ANALYSIS}

\section{A. Variable Selection and Explaination}

This paper analyzes panel data of 30 provinces, municipalities and autonomous regions (excluding Tibet) in China from 2006 to 2012. All energy data obtained from China Energy Statistical Yearbook and the rest of data are 
from CEInet Statistical Database. It abandons traditional industrial wastewater, industrial exhaust and industrial waste as representative indicator of environment quality, but selects $\mathrm{CO}_{2}$ emission, which is highly correlated with energy consumption. Other indicators include economic scale (GDP), the population of people $\left(P O P_{i t}\right)$, urbanization, industrial level, FDI as well as liberalization. Where urbanization $\left(U R B_{i t}\right)$ means the ratio of urban population to total population in each region, industrial level $\left(I N D_{i t}\right)$ means the ratio of industrial added value in each region, $F D I_{i t}$ means actual utilized amount of FDI and trade liberalization $\left(T R A_{i t}\right)$ means the ratio of import and export amount to GDP. We have 210 observations for each variable.

\section{B. Carbon Dioxide Emission Estimation}

In China, there is no direct test data for emission of carbon dioxide emission. Therefore, most of researchers estimated it by using energy consumption multiplies carbon emission coefficient for different types of energy.

$$
\mathrm{CO}_{2}=\sum E_{i} \times F_{i} \times 44 / 12
$$

where $E_{i}$ is energy consumption, $F_{i}$ is carbon emission coefficient for different types of energy, 44/12 is transition coefficient. The values of $F_{i}$ show in Table I.

According to the table, we calculate 210 carbon dioxide emission observations for 30 regions from 2005 to 2012.

TABLE I. $\quad \mathrm{CO}_{2}$ COEFFICIENT FOR DIFFERENT TYPES OF ENERGY

\begin{tabular}{|c|c|c|c|c|}
\hline Type & Coal & Oil & Natural Gas & $\begin{array}{l}\text { water } \\
\text { electricity } \\
\text { and nuclear } \\
\text { electricity }\end{array}$ \\
\hline $\begin{array}{c}F_{i} \text { (tons of } \\
\text { carbon/10000 tons } \\
\text { of standard coals) }\end{array}$ & 0.7476 & $\begin{array}{c}0.58 \\
25\end{array}$ & 0.4435 & 0.0 \\
\hline
\end{tabular}

\section{Single factor PSTR Model Construction}

First, all variables are used in logarithmic to reduce the impact of heteroscedasticity. Second, to avoid spurious regression and ensure the validity of the estimation results, we use the LLC test under the same unit root to inspect seven variables panel sequence stability, and find out all of them show one-order integration. Finally, after cointegration test for the panel data using Pedroni and Kao test, we find out that panel data of seven variables have long-term stable equilibrium. Based on the test above, we will use four factors as transition variables to build up four PSTR models in order to fully examine the influences of urbanization, industrial level, FDI and trade liberalization on the relations between economic growth and environmental pollution.

1) Single factor PSTR model Setting and Test

We use $\ln C O_{2 i t}$ and $\ln G D P_{i t}$ to represent logarithm of $\mathrm{CO}_{2}$ and GDP respectively, and take urbanization, industrial level, FDI and liberalization as transition variables and construct four models to represent indirect influence on environment. We denote them as model 1 to 4 respectively, and each variable corresponds to a transition model.

According to Table II, all four models represented by four transition variables reject the null hypothesis, which means nonlinear transferring effect assumption hold, and it is suitable to build PSTR models.

TABLE II. SINGLE FACTOR PSTR NONLINEAR TEST RESULTS

\begin{tabular}{c|c|c|c|c}
\hline Model & $\begin{array}{c}\text { Transition } \\
\text { Model }\end{array}$ & $\begin{array}{c}\text { Wald Tests } \\
(\mathbf{L M})\end{array}$ & $\begin{array}{c}\text { Fisher Tests } \\
\text { (LMF) }\end{array}$ & $\begin{array}{c}\text { LRT Tests } \\
\text { (LRT) }\end{array}$ \\
\hline \multirow{2}{*}{1} & $\ln U R B_{i t}$ & 29.721 & 14.672 & 32.046 \\
& & $(0.000)$ & $(0.000)$ & $(0.000)$ \\
2 & $\ln I N D_{i t}$ & 7.823 & 3.444 & 7.972 \\
& & $(0.020)$ & $(0.034)$ & $(0.000)$ \\
3 & $\ln F D I_{i t}$ & 28.756 & 14.121 & 30.925 \\
& & $(0.004)$ & $(0.007)$ & $(0.000)$ \\
4 & $\ln T R A_{i t}$ & 4.985 & 2.124 & 4.953 \\
& & $(0.087)$ & $(0.123)$ & $(0.008)$ \\
\hline
\end{tabular}

a. Numbers in bracket represent p value respectively (same as the following tables)

\section{2) Single Factor PSTR Model Selection}

Next we examines the optimal number of transition function when location parameter taking 1 or 2 respectively, and calculates the corresponding residual sum of squares, AIC and BIC value as following Table III.

After considering residual sum of squares and value of AIC and BIC, the optimal number of location parameter and transition function both is 1 for model 1 and 4, (2,1) for model 2 and $(1,2)$ for model 3.

TABLE III. NUMBER OF LOCATION PARAMETER SELECTION

\begin{tabular}{|c|c|c|c|c|c|c|}
\hline $\begin{array}{l}\text { Mo } \\
\text { del }\end{array}$ & $\begin{array}{c}\text { Transition } \\
\text { Variable }\end{array}$ & $\begin{array}{c}\text { Number } \\
\text { of } \\
\text { Location } \\
\text { Paramet } \\
\text { er }\end{array}$ & $\begin{array}{c}\text { Optimal } \\
\text { number } \\
\text { of } \\
\text { transitio } \\
n \\
\text { function }\end{array}$ & RSS & AIC & BIC \\
\hline \multirow{2}{*}{1} & \multirow{2}{*}{$\ln U R B_{i t}$} & $m=1$ & 1 & 1.233 & -5.05 & -4.91 \\
\hline & & $m=2$ & 1 & 1.233 & -5.03 & -4.90 \\
\hline \multirow{2}{*}{2} & \multirow{2}{*}{$\ln I N D_{i t}$} & $\mathrm{~m}=1$ & 1 & 1.156 & -5.11 & -5.05 \\
\hline & & $m=2$ & 1 & 1.343 & -4.95 & -4.86 \\
\hline \multirow{2}{*}{3} & \multirow{2}{*}{$\ln F D I_{i t}$} & $\mathrm{~m}=1$ & 2 & 1.065 & -5.16 & -4.93 \\
\hline & & $\mathrm{m}=2$ & 2 & 1.072 & -5.13 & -4.82 \\
\hline \multirow{2}{*}{4} & \multirow{2}{*}{$\ln T R A_{i t}$} & $\mathrm{~m}=1$ & 1 & 1.477 & -4.87 & -4.77 \\
\hline & & $m=2$ & 1 & 1.660 & -4.75 & -4.65 \\
\hline
\end{tabular}

3) Single factor PSTR Model Parameters Estimation

The paper uses nonlinear LS method to estimate parameters, the initial value of slope and location parameter was determined by grid search approach. Model 1, 2 and 4 are two-mechanism models with one location parameter, one transition variable and one slope parameter, and model 3 is three-mechanism model with two location parameters, three transition variables and three slope parameters. Specific parameters of each model are shown in Table IV. 
TABLE IV. SINGE FACTOR PSTR MODEL ESTIMATION RESULT

\begin{tabular}{c|c|c|c|c}
\hline Model & Model 1 & Model 2 & Model 3 & Model 4 \\
\hline $\begin{array}{c}\text { Transition } \\
\text { Variable }\end{array}$ & $\ln U R B_{i t}$ & $\ln I N D_{i t}$ & $\ln F D I_{i t}$ & $\ln T R A_{i t}$ \\
\hline$\left(m, l^{*}(m)\right)$ & $(1,1)$ & $(1,1)$ & $(1,2)$ & $(1,1)$ \\
\hline$\beta_{0}$ & 0.359 & 1.176 & 0.452 & 0.492 \\
$\beta_{0}^{1}$ & $(12.308)$ & $(5.613)$ & $(17.933)$ & $(20.007)$ \\
$\beta_{0}^{2}$ & 0.180 & -0.720 & 0.074 & 0.035 \\
$\gamma_{1}$ & $(5.142)$ & $(-3.415)$ & $(9.613)$ & $(1.800)$ \\
$\gamma_{2}$ & - & - & -0.041 & - \\
$c_{1}^{1}$ & 15.260 & 24.333 & 10.760 & 10.392 \\
$c_{2}^{1}$ & - & - & 14.227 & - \\
$c_{1}^{2}$ & 3.838 & 3.175 & 5.301 & 3.419 \\
$c_{2}^{2}$ & - & - & - & - \\
\hline
\end{tabular}

Table IV shows that there exist positive correlation between effect of economic growth on environmental pollution and urbanization and trade liberalization, the higher these values are, the greater effects of economic growth on environmental pollution. Oppositely, industrial level shows the negative relations, where the higher industrial level results in the lower effect economic growth on environmental pollution. More specially, FDI shows the trend from positive to negative relations. Besides, slope parameters in four models are moderate, which demonstrates the smooth transition of effect between low and high mechanism when urbanization, industrial level, FDI and trade liberalization are treated as internal mechanism. Specific transition process of four models shows in Figure 1 to Figure 4, and the explanations are followed.

a) Urbnization and Effect of Economic Growth on Environmental Pollution

The estimation results above show a positive correlation between effect of economic growth on environmental pollution and urbanization with one location parameter and one transition function. $\ln U R B_{i t}>3.838$ means the model 1 tends to be high mechanism when urbanization is greater than $46.43 \%$. Since the slope parameter is 15.26 , it transits smoothly between high and low mechanism of effects of economic growth on environmental pollution with the changes of urbanization value.

Model 1 demonstrated that the higher urbanization is, the greater elasticity economic growth to environmental pollution corresponding with general experience. Since production in rural area is more environmental friendly than in urban, it is natural that less carbon dioxide emission each unit GDP growth. In 30 regions, the greatest urbanization regions are Shanghai and Bejing, where all sample values are above threshold, and the elasticity is 0.576 , which means $1 \%$ GDP growth will increase $0.539 \%$ carbon dioxide emission. Oppositely, the lowest urbanization regions are Guizhou and Yunan provinces, where the sample values are under threshold, and elasticity is 0.359 , which means $1 \%$ GDP growth will increase $0.359 \%$ carbon dioxide emission.

b) Industrial Level and Effect of Economic Growth on Environmental Pollution

The estimation results above show a negative correlation between effect of economic growth on environmental pollution and industrial level with one location parameter and one transition function. $\ln I N D_{i t}>3.175$ means the model 2 tends to be high mechanism when urbanization is greater than $23.923 \%$. Meanwhile, since the moderate slope parameter is 24.333, it transits smoothly between high and low mechanism of effect of economic growth on environmental pollution with the changes of industrial level.

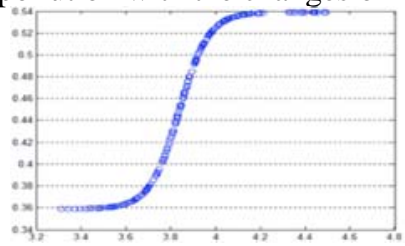

Figure 1. The Relaiton Between Urbnization (X-axis) and Effect of Economic Growth on Environmental Pollution (Y-axis)

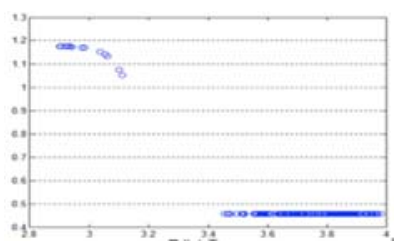

Figure 2. The Relaiton Between Industrial Level (X-axis) and Effect of Economic Growth on Environmental Pollution (Y-axis)

In Figure 2, apparently reducing tendency samples are from Beijing and Hainan, where both industrial added values over GDP ratios are long stable at relative low level. Therefore, the small changes in industrial level would cause great fluctuation on elasticity. Consequently, samples of $\operatorname{lnIND}_{i t}>3.4$ are from the rest of 28 regions, where keeps relative high industrial level, and low fluctuation on elasticity correspondingly. In the model 2, the minimum value of $\operatorname{lnGDP}$ is around 0.45 , where $1 \%$ growth in GDP will increase $0.45 \%$ carbon dioxide emission.

c) FDI and Effect of Economic Growth on Environmental Pollution

The estimation results above show a correlation transiting from positive to negation with two transition functions and two slope and location parameters respectively. In low mechanism, More FDI would result in greater effect of economic growth on environmental pollution. However, in high mechanism is, the more FDI the less effect is. Beside, since the two slope parameters are moderate, Figure 3 shows a smooth transit for the elasticity with different FDI values.

Model 3 identifies that more FDI will weaken the effect of economic growth on environmental pollution when FDI is over 6.229 billion USD which is also the second threshold. Up to 2012, the number of regions over the second threshold is 11. Although more FDI may have the possibility to ease environmental pollution, it is pity shown in Figure 3 that the 
decreasing range in high mechanism curve is relatively smaller than increasing range in low mechanism, which means the more FDI to lower the effect of economic growth on environmental pollution cannot make up the opposite effect. Meanwhile, negative effect of FDI on the environmental pollution effect tends to be stable.

d) Trade Opennes and Effect Economic Growth on Environmental Pollution

Like model 1 , it is positive relations with one location parameter and on transition function. $\operatorname{lnTRA}_{i t}>3.419$ means model transit to high mechanism when trade amounts to $30.54 \%$ of GDP. Since slope parameter is 10.392 , it transits smoothly between high and low mechanism of effect of economic growth on environmental pollution with the changes of trade liberalization.

Ceteris paribus, model 4 demonstrates the more open trade is, the more effect of economic growth on environmental pollution. The most open regions are Shanghai and Beijing, with all sample above threshold. Elasticity of economic growth to environmental pollution is 0.527 , which means $1 \%$ of GDP growth will cause the climb of $0.527 \%$ carbon dioxide emission. Oppositely, the least open regions are Qinghai and Guizhou province where all sample values are under threshold, and the elasticity is 0.429 , which means $1 \%$ of GDP growth will advocate $0.492 \%$ of carbon dioxide emissions.

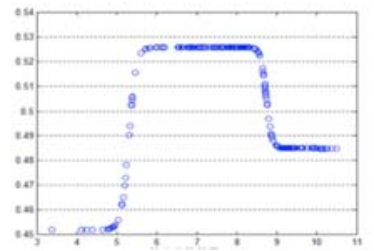

Figure 3. The Relaiton Between FDI (X-axis) and Effect of Economic Growth on Environmental Pollution (Y-axis)

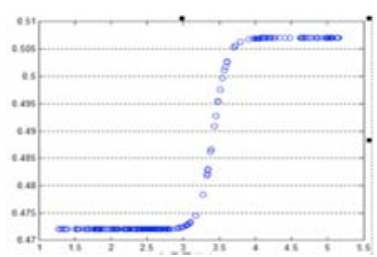

Figure 4. The Relaiton Between Trade Opennes (X-axis) and Effect of Economic Growth on Environmental Pollution (Y-axis)

\section{MULTIFACTOR PSTR MODEL CONSTRUCTION AND ANALYSIS}

From analysis above, four transition variables all have indirect impact on effect of economic growth on environmental pollution. In reality, excepted for population, different indirect factors also impose influence on the effect. Moreover, this part chooses 6 indicators as dependent variables excluding carbon dioxide in order to estimate economic scale threshold value. Different from traditional PSTR model, this part construct multivariate PSTR model using representative indicator $\ln G D P_{i t}$ as economic scale. a) Multifactor PSTR Model Setting and Test Multifactor PSTR Model 5 setting is followed: $\ln C O_{2 i t}=\mu_{i}+\beta_{0} \ln G D P_{i t}+\beta_{1} \ln P O P_{i t}+\beta_{2} \ln U R B_{i t}+\beta_{3} \ln I N D_{i t}+\beta_{4} \ln F D I_{i t}+\beta_{5} \ln T R A_{i t}$ $+\left(\beta_{0}^{1} \ln G D P_{i t}+\beta_{1}^{1} \ln P O P_{i t}+\beta_{2}^{1} \ln U R B_{i t}+\beta_{3}^{1} \ln I N D_{i t}+\beta_{4}^{1} \ln F D I_{i t}+\beta_{5}^{1} \ln T R A_{i t}\right)$ $g\left(\ln G D P_{i t} ; \gamma, c\right)+\varepsilon_{i t}, i=1,2, \cdots, N, t=1,2, \cdots, T$

TABLE V. NONLINEAR TEST OF MULTIFACTOR PANED MODEL

\begin{tabular}{c|c|c|c}
\hline $\begin{array}{c}\text { Null and Alternative } \\
\text { Hypothesis }\end{array}$ & $\begin{array}{c}\text { Wald } \\
\text { Tests } \\
\text { (LM) }\end{array}$ & $\begin{array}{c}\text { Fisher Tests } \\
\text { (LMF) }\end{array}$ & $\begin{array}{c}\text { LRT Tests } \\
\text { (LRT) }\end{array}$ \\
\hline$H_{0}: \gamma=0$ vs $H_{1}: \gamma=1$ & 122.262 & 19.509 & 183.279 \\
$H_{0}^{\prime}: \gamma=1$ vs $H_{1}^{\prime}: \gamma=2$ & $(0.000)$ & $(0.000)$ & $(0.000)$ \\
& 52.745 & 4.360 & 60.741 \\
& $(0.000)$ & $(0.000)$ & $(0.000)$ \\
\hline
\end{tabular}

From Table V, it is significant nonlinear test in multifactor panel model, in which nonlinear transition effect holds.

b) Multifactor PSTR Parameter Estimation

In Table $\mathrm{V}$, model 5 rejects $H_{0}$ and $H_{0}^{\prime}$, therefore we choose $r=2$. After checking sequential test, AIC and BIC, we get $m=2$. The results of parameter estimation are shown in Table VI.

TABLE VI. ESTIMATION RESULTS OF MULTIFACTOR PSTR MODEL

\begin{tabular}{|c|c|c|c|c|c|}
\hline $\begin{array}{c}\text { Paramet } \\
\text { er }\end{array}$ & $\begin{array}{c}\text { Estimati } \\
\text { on }\end{array}$ & $\begin{array}{c}\text { Paramet } \\
\text { er }\end{array}$ & $\begin{array}{c}\text { Estimati } \\
\text { on }\end{array}$ & $\begin{array}{c}\text { Paramet } \\
\text { er }\end{array}$ & $\begin{array}{c}\text { Estimati } \\
\text { on }\end{array}$ \\
\hline$\beta_{0}$ & $\begin{array}{c}1.218 \\
(12.134)\end{array}$ & $\beta_{0}^{1}$ & $\begin{array}{c}-0.833 \\
(-2.757)\end{array}$ & $\beta_{0}^{2}$ & $\begin{array}{c}-0.878 \\
(-8.525)\end{array}$ \\
\hline$\beta_{1}$ & $\begin{array}{c}1.808 \\
(4.583)\end{array}$ & $\beta_{1}^{1}$ & $\begin{array}{c}3.428 \\
(2.376)\end{array}$ & $\beta_{1}^{2}$ & $\begin{array}{c}1.581 \\
(7.017)\end{array}$ \\
\hline$\beta_{2}$ & $\begin{array}{c}1.512 \\
(3.955)\end{array}$ & $\beta_{2}^{1}$ & $\begin{array}{c}-0.513 \\
(-0.802)\end{array}$ & $\beta_{2}^{2}$ & $\begin{array}{c}-2.033 \\
(-5.163)\end{array}$ \\
\hline$\beta_{3}$ & $\begin{array}{c}1.775 \\
(8.829)\end{array}$ & $\beta_{3}^{1}$ & $\begin{array}{c}2.717 \\
(4.391)\end{array}$ & $\beta_{3}^{2}$ & $\begin{array}{c}-1.556 \\
(-8.150)\end{array}$ \\
\hline$\beta_{4}$ & $\begin{array}{c}0.248 \\
(4.067)\end{array}$ & $\beta_{4}^{1}$ & $\begin{array}{c}0.215 \\
(3.056)\end{array}$ & $\beta_{4}^{2}$ & $\begin{array}{c}-0.266 \\
(-3.973)\end{array}$ \\
\hline$\beta_{5}$ & $\begin{array}{c}0.100 \\
(1.944)\end{array}$ & $\beta_{5}^{1}$ & $\begin{array}{c}-0.168 \\
(-1.273)\end{array}$ & $\beta_{5}^{2}$ & $\begin{array}{c}-0.135 \\
(-2.534)\end{array}$ \\
\hline$\gamma_{1}$ & 2.339 & $\gamma_{2}$ & 3.008 & $c_{1}^{1}$ & 7.159 \\
\hline$c_{2}^{1}$ & 11.825 & $c_{1}^{2}$ & 10.258 & $\beta_{0}$ & 10.258 \\
\hline AIC & -5.382 & BIC & -4.999 & RSS & 0.677 \\
\hline
\end{tabular}

From Table VI, the Model 5 is statistically significant. Compared with single factor model, AIC, BIC and residual sum of squares in multifactor model all turns down, where residual sum of squares decrease the most. Consequently, multifactor model may better explain the nonlinear effect of economic growth on environmental pollution.

Economically, population, industrial level, FDI and trade liberalization all have significant effect on pollution. And combined all these impacts, economic growth has a more significant influence on the effect. Linear parameters are positive which testifies the positive correlation between economic growth and environmental pollution, but the nonlinear parameters $\beta_{0}^{1}$ and $\beta_{0}^{2}$ are negative, which turns out the negative nonlinear effect of economic growth on 
environmental pollution, where the increasingly lower impact on environmental pollution when economy grows and even have negative correlation when it breaks some point. It matches EKC hypothesis.

Specifically, it can be seen in Figure 5 that there are two transition functions, $g_{1}$ and $g_{2}$, and two location parameters 7.159 and 10.258 under the sample observation range. The first transition function $g_{1}$ shows systematic effect on the two sides of threshold value 7.159 , where economic impact on environmental pollution expands gradually when provincial GDP is lower 128.6 billion Yuan and keeps decreasing, and vice versa. In the second transition function $g_{2}$, it has reverse impact around two sides of threshold value 10.258, where economic impact on environmental pollution elevates gradually when provincial GDP lower and keep lowering than the threshold 2.85 trillion Yuan, and when GDP is higher 2.85 trillion and keeps increasing, the effect expands. As a result of both transition functions, the general model around the both sides of threshold shows asymmetric influence shown in Figure 6.

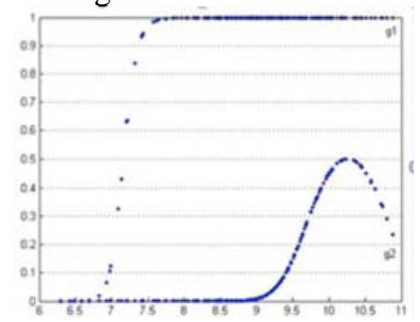

Figure 5. Transition Function when $\gamma=2$, where $\mathrm{X}$-axis is economic scale $\ln G D P_{i t}$ and $\mathrm{Y}$-axis is transition function

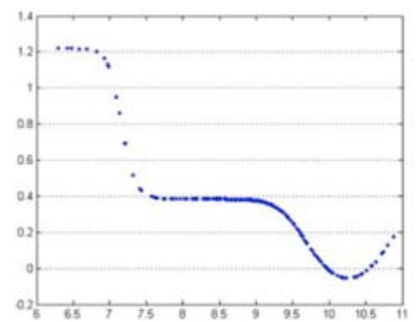

Figure 6. Nonlinear Effect of Economic Growth on Environmental Pollution, where $\mathrm{X}$-axis is $\ln G D P_{i t}$ and $\mathrm{Y}$-axis is coefficient of $\ln G D P_{i t}$.

From Equation (5), coefficient of $\ln G D P$ represents marginal effect of economic growth on environmental pollution. From Figure 6, it is shown that when Provincial GDP is smaller than 128.6 billion Yuan and keeps reducing, marginal effects expand with maximum coefficient 1.218, in which $1 \%$ more provincial GDP results in $1.218 \%$ of carbon dioxide emission. When provincial GDP is in between 128.6 billion and 2.851 trillion Yuan and keep growing, marginal effect weakens. Especially, when $\ln G D P$ is within [10.0, 10.5], where provincial GDP is in between 2.20 and 3.63 trillion Yuan, marginal effects shows negative, where pollution was alleviated by economic growth. In real provincial data, some regions are experiencing from positive marginal effect to negative with the moderate economic growth. For example, GDP of Hubei and Hunan provinces in 2010 broke the most left point of optimal provincial GDP interval, which is 2.21 trillion Yuan. Oppositely, some regions such as Guangdong province is experiencing negative marginal effect to positive after broke the threshold value with the speeding economic growth, where its GDP in 2008 has already broke the most right point of optimal GDP interval, and climbed up to 5.70billion in 2012.

\section{CONCLUSION AND POLICY SUGGESTIONS}

In this paper, we examine the indirect influence of urbanization, industrial, FDI and trade liberalization on environmental pollution through singe factor PSTR, and study the nonlinear effect between provincial economic growth and environmental pollution through multifactor PSTR. The conclusion and policy meanings are followed:

First, the effect of economic growth on environmental pollution can be divided by PSTR model into two parts: some are fixed growth effect, that is, it does not change with time and region; others are random growth effect, that is, it shows a certain part of regular change under different conditions with changes of time and regions. Each model embodies the features that the effect will change with different variables' values centering on threshold. It depicts the dynamic change process of the model in details.

Second, ceteris paribus, it demonstrates significant nonlinear effect of provincial economic growth on environmental pollution with different impact from four factors. In general, the indirect impact of industrial level on environmental pollution is relatively lower than other three. Meanwhile, elasticity of economic growth to environmental pollution is greater in higher urbanization, FDI and trade liberalization regions. Slight differently, effect of economic growth on environmental pollution can be reduced when FDI is over certain amount. Besides, when provincial GDP is lower than 2.85 trillion Yuan, effect of economic growth on environmental pollution descends gradually, and vice versa. The optimal provincial GDP interval is [2.20, 3.63] trillion Yuan, where the marginal effect is negative and economic growth can alleviate environmental pollution.

Third, essentially, China should control economic growth moderately through various indirect factors reaching the optimal level to improve the current environment deterioration. Specifically, although it is possible to weaken the deterioration process through introducing FDI, the result is limited and still about half of the regions do not reach the threshold value. Therefore, it is not wise to introduce FDI blindly. Additionally, the effect of economic growth on environmental pollution has already exacerbated under the influence of urbanization and trade liberalization. Even though the indirect impact of industrial level barely maintains within acceptable limits, general environmental situation in China is grim. During the process of economic development, urbanization and trade liberalization indirectly affect the local environment through influence on economic scale, industrial structure as well as technological advancement; developed countries transfer their pollutionintensive industries to developing countries, so that it also has negative impact on China's environment. Therefore, it is 
not possible to repeat the path "pollution first, governance after" like developed countries, facing the dilemma of gradual environmental deterioration and resource shortage. China, as a developing country, should choose the development path to change economic growth method, optimize industrial structure and form the comprehensive development structure with the guidance of high-tech industry and full development of modern service, manufacture and agriculture industries. Especially, China should emphasize on emerging industries such as information, culture, ecological industries such as energy saving, environmental-friendly and new energy, based on promoting industrial technology level, eliminating inefficient capacity in order to form a modern and efficient industrial system with low energy consumption and carbon emission and more investment abroad. In return China will reach the win-win situation of economic growth and environmental improvement.

\section{ACKNOWLEDGMENT}

This work was supported by Humanities and Social Sciences Foundation of Ministry of Education of China (15JJD790029 \& 13YJA9100002) and National Social Sciences Foundation of China (16BTJ018).

\section{REFERENCES}

[1] Meadows, D. H., D. L. Meadows, J. Randers and W. W. Behrens. The Limits to Growth[M]. New York: Universe Books, 1972.

[2] Grossman, G. M. and A. B. Krueger. Environmental Impacts of a North American Free Trade Agreement[R]. NBER Working Paper, 1991.

[3] Thomas M. S. and D. Song. Environmental Quality and Development: Is There a Kuznets Curve for Air Pollution Emissions?[J]. Journal of Environmental Economics and Management, 1994, (2).

[4] Unruh G. C. and W. R. Moomaw. An Alternative Analysis of Apparent EKC-type Transitions[J]. Ecological Economics, 1998, (2).

[5] Antweiler W, B.R., Copeland and M. S. Taylor. Is Free Trade Good for the Environment ?[J]. American Economic Review, 2001, (91).

[6] Gonzalez A., T. Teräsvirta and D. Van Dijk. Panel Smooth Transition Regression Model and an Application to Investment under Credit Constraints[R]. Working Paper, 2004.

[7] Bruce E.H. Threshold Effects in Non-dynamic Panels: Estimation, Testing and Inference[J]. Journal of Econometrics, 1999, (2).

[8] Colletaz G. and C. Hurlin. Threshold Effects in the Public Capital Productivity: An International Panel Smooth Transition Approach [R]. Working Papers, 2006.

[9] Lu N. and G. Li. Research on Impact of Capital Level to Environmental Quality - Based on Panel Data from 1995 to 2007 in China [J]. Statistical Research, 2009, (5).

[10] Su W. and C. Zhang. Retest of EKC in China Based on Heterogeneity [J]. Statistical Research, 2011, (12).

[11] Fu M. EKC in China: Formation, Turning Point and Influcen Factors [J]. The Journal of Quantitative and Technical Economics , 2008, (11). 